\title{
EDUCAÇĀO RURAL EM LONDRINA: cotidiano e cidadania
}

\section{Maria Regina Clivati Capelo:}

\begin{abstract}
Após ressaltar certas especificidades das escolas rurais isoladas na realidade londrinense, 0 presente artigo enfatiza a análise do cotidiano escolar-rural através das memórias de professores, pais de alunos, ex-alunos. $\mathrm{O}$ aprofundamento das relações capitalistas engendra o esvaziamento do campo e a conseqüente agonia das escolas isoladas. A política de nucleação dessas escolas, desenvolvida, em Londrina, pela Secretaria Municipal de Educação, simboliza a modernização do modo de ensinar tipicamente rural, entretanto, tal proposta encontrou certas resistências, especialmente em comunidades compostas por pequenos produtores. Essa resistência, mediada pela memória, é tomada como elemento chave para ressignificar a própria escola, a identidade e a coesão social, reafirmando o pertencimento ao mundo rural. Registrar essas manifestações de resistência e o processo de construção da cidadania, através da escola rural isolada, é o objetivo mais preciso deste artigo.
\end{abstract}

Palavras-chave: Educação Rural, Memória, Cidadania

\section{Introdução}

A té os anos 90, as "escolinhas" rurais isoladas de Londrina, ainda que rarefeitas de alunos, resistiram bravamente as tentativas de expropriação engendradas pela modernização da agricultura. O aprofundamento das relações capitalistas no campo, representado pela tecnificação da produção agrícola e substituição da monocultura do café pela policultu$\mathrm{ra}$, vem acompanhado de altas taxas de urbanização, reconcentração da terra e desruralização, fazendo crer, ao nível do senso comum, que o rural esteja desaparecendo. Ao contrário dessa impressão, a proposta de nucleação das escolas rurais isoladas de Londrina, evidenciou a presença ativa de pequenos produtores rurais que procuram não sucumbir ao processo de expropriação, revelando, ao mesmo tempo, o modo de vida, valores, tradições e o enorme apego que dedicam aos bens culturais que os cercam, especialmente a "escolinha" e a igreja

Na escola são depositadas as esperanças de um futuro retratado no pertencimento dos filhos ao mundo rural. As discussões que a Secretaria Municipal de Educação desencadeou com as comuni- dades rurais para apresentar o projeto de agrupamento de algumas escolas isoladas, revelaram um lado ainda pouco pesquisado da educação rural, particularmente quando se trata de enfocá-la sob o ângulo de quem dela necessita.

\section{Escola rural isolada: à procura de sua identidade}

Tomando o termo escola em sua acepção genérica, verifica-se que ela pode ser analisada mediante diferentes perspectivas: através das subjetividades e expectativas que para ela confluem, dos papéis político-ideológicos que desempenha no contexto da sociedade inclusiva, da realidade objetiva da própria escola, etc.

Ressalvando o fato de que a escola não se resume ao aparelho arquitetônico, creio que uma breve apreciação dos prédios que abrigam as escolas isoladas, será bastante útil para que se materialize uma espécie de retrato das suas condições objetivas pois, do espaço físico emerge o espaço pedagógico

\footnotetext{
- Prof do Departamento de Ciências Sociais da Universidade Estadual de Londrina
} 
e, em certa medida, este encontra-se condicionado por aquele.

Tornou-se bastante usual, nos discursos acadêmicos, aplicar a palavra escola com intenção globalizante. Raras vezes a escola é identificada em suas especificidades: existem escolas públicas, privadas, rurais, intinerantes, etc...

A escola rural isolada é um caso muito especial de instituição escolar pois difere, em quase tudo, do modelo considerado padrão. As diferenças começam a ser percebidas a partir do próprio nome: escola isolada, separada, solitária, pouco frequentada, situada em local de dificil acesso. É preciso, entretanto, diferenciar entre a escola isolada e aquela localizada no Distrito ou Patrimônio-sede. São duas escolas pois o isolamento do Distrito não é tão incidente quanto o que ocorre nas fazendas, particularmente pelas dificuldades de transporte . $^{.33}$

De acordo com o lugar onde os alunos residem, as escolas distam até $6 \mathrm{~km}$. Embora a distância seja variável, as escolas isoladas apresentam-se como algo próximo e próprio da comunidade. Em algumas localidades a casa do professor e a igreja estão situadas ao lado da escola, simbolizando as estreitas relações existentes nas comunidades entre fé e educação. Onde a igreja não tem abrigo, a própria escola se transforma no templo incorporando a sagrado.

As escolas estão construídas em terrenos cedidos, em comodato, à Prefeitura por sitiantes e fazendeiros. Assemelham-se a uma casa bastante simples, de madeira. Interessante verificar que muitas placas de identificação das escolas, ostentam a inscrição: "uma extensão do seu lar", numa referência às especificidades da escola enquanto espaço de socialização no meio rural que traduz relações de proximidade, afeto e continuidade dos laços familiares 34

No interior das escolas, os painéis mostram trabalhos e notícias de jornal. A escola se resume à sala, portanto, não existe biblioteca, embora os livros constituam ferramentas essenciais para o ensino e aprendizagem. Dentro da "casa escolar", a criatividade faz nascer, em uma carteira com alguns livros dispostos numa sacola, a biblioteca possivel no contexto do isolamento.

Em grande parte das escolas isoladas, as carteiras acolhem dois alunos de uma só vez, contrariando a idéia de individualismo que prevalece quando se trata de carteiras unidiscentes. Estudar a dois pode significar que 0 isolamento da escola está sendo rupturizado a cada encontro de trabalho. Do ponto de vista pedagógico, essas carteiras são um sinal de que a prática educativa pode variar em

\footnotetext{
33 A administração das isoladas é realizada pela Secretaria Municipal de Educação, através de núcleos de supervisão escolar instalados nas sedes dos Distritos que funcionam como intermediários entre a Secretaria e as escolas isoladas.

34 Escolas Benjamim Constant e André Rebouças, entre outras, situadas em Lerrovile, Distrito de Londrina.
}

consonância com as posições que os alunos tomam e das séries em que se situam. Da proximidade pode resultar uma troca de conhecimento entre os estudantes cujas séries são diferentes 35 . Ao que tudo indica a organização do ensino enraíza-se na concepção de que a escola isolada desempenha a tarefa de ensinar a ler, escrever e contar. Isto significa que a tarefa da escola está relacionada à transmissão e assimilação de conhecimentos científicos, geralmente selecionados de fora para dentro, ou mais precisamente de forma arbitrária. Porém o papel da escola extrapola esse patamar na medida em que:

"Por intermédio de práticas particulares de ensino, valores, hábitos atitudes e comportamentos são também socializados. Este conjunto de ensinamentos pode ser reproduzido ou superado dependendo dos processos sociais e dos padrões de interação que o definem e lhe dão sentido". (DAVIS \& GATTI, 1993, p. 75).

As multisseriação foi solução encontrada para atender as demandas por educação na zona rural. $\mathrm{Da}$ ótica do poder público, uma solução de baixo custo. Para os professores que se submetem a um cotidiano de trabalho no qual desempenham todo o tipo de tarefa, as dificuldades e responsabilidades são redobradas. Atender, a um só tempo, alunos de séries diferentes exige criatividade, segurança e um conhecimento da realidade do aluno que, muitas vezes, são aspectos ignorados nos cursos de formação de professores.

A sensação primeira de que, na escola rural isolada, a atividade pedagógica de processa de acordo com o arbítrio dos próprios professores, é diluída quando se verifica que, na realidade de Londrina, o serviço de supervisão escolar pode ser caracterizado como muito atuante. Em geral os supervisores residem nas proximidades das escolas, intensificando os contatos com professor das isoladas.

A criação do serviço de inspeção escolar remonta ao início dos anos 50. Sua atuação possuía um caráter "controlador" da autonomia docente. Nas ocasiões das visitas de "inspeção", todos os aspectos eram observados: a limpeza, ordem dos livros, diários, semanários e pautas de chamada, nas quais atentava-se para seu correto preenchimento, inclusive se estavam preenchidas à tinta. Comumente nos fatídicos dias 25 de cada mês, realizavam-se as temidas "sabatinas" que se compunham de ditados, redação, cinco problemas de Aritmética, de perguntas de Conhecimentos Gerais, etc. Todas as minúcias sobre a atuação do professor eram detalhadas através de "circulares" elaboradas pelo Departamento de Educação Pública e Assistência Social.

35 Alunos de séries mais avançadas comumente transformavam-se em monitores, auxiliando os mais jovens quanto à compreensão das atividades escolares. 
Uma incursão aos anos 40 , no periodo que antecede à criação do Departamento de Educação Pública e Assistência Social (DEPAS), revela que, de fato, o professor era mais livre quanto ao "fazer pedagógico", o controle do professor era atribuído pelo poder público, aos proprietários - fundadores de algumas escolas que desempenhavam uma espécie de "supervisão" no sentido mais direto de atestar a assiduidade dos professores. Ainda que 0 caráter controlador da supervisão escolar possa existir pois o supervisor é aquele que dirige, orienta ou inspeciona de um plano superior, na atualidade, parece prevalecer uma interação mais voltada às práticas pedagógicas.

Apesar das diferenças marcantes da escola isolada em comparação com as unisseriadas, as propostas pedagógicas (currículo, programas, conteúdos, provas, etc...) são formulados, a partir de referências urbanas, por técnicos da Secretária de Educação. Em tese, a política educacional direciona, mesmo que possa não pretender, as práticas pedagógicas imprimindo características ambíguas à educação rural. Não se configura portanto, como educação rural (agrícola) e nem como educação urbana. Além disso, a idéia de inferioridade do "locus" rural comparativamente ao urbano, consciente ou inconscientemente, encontra reforço no processo de formação docente como uma reminiscência cultural que atravessa os séculos, desde a colonização do país.

Hoje as escolas e, mais diretamente seus professores, têm maior liberdade para planejar o ensino e formular avaliações. Mesmo considerando a existência dessa liberdade é importante ressaltar que o conhecimento da realidade social rural deve ser a fonte das definições político pedagógicas na escola rural. Não se trata, obviamente de enclausurar a práxis pedagógica no "ethos" do ruralismo36. Trata-se, na verdade, de encarar com clareza a presença das relações de produção capitalista no campo forjando situações de sub-emprego, desemprego, contradições e dicotomias. Se este é o grande problema, não se pode negar que os cursos de formação de professores têm sua parcela de responsabilidade pois, na medida em que privilegiam aspectos técnicos - metodológicos da educação, deixam para um plano secundário as questões político - sociológicas e a pesquisa educacional. Ademais, há que se atentar para o fato de que o aumento das migrações da força de trabalho rural empregada como temporária, adiciona um outro proble-

36 Corrente politico - ideológica, de cunho conservador, que propunha, nos anos 30 , a adequação da educaçăo rural às condições locais para "fixar"o homem no campo. A permanência seria alcançada através da educação escolar. Ao professor incumbia a missão de convencer o homem rural a perceber como "natural" sua situação de marginalidade pelo ocultamento das contradições presentes na sociedade. (MAIA, Eni Marisa. A Educação Rural no Brasil. O que mudou em 60 anos? In: ANDE. Revista de Associação Nacional de Educação. São Paulo, v. 1, n. 3, p. 5-6, 1982. ma: o que ocorre com a criança, que também é migrante, com relação ao aproveitamento escolar?

\section{Passado e presente: as práticas pedagógicas em questão}

A proposta de nucleação das escolas rurais está fundamentada no aprimoramento da qualidade do ensino. À medida que esse argumento apareceu no discurso oficial, instigou os pais a relembrarem de suas próprias experiências escolares, transferindoas do passado para o presente, na forma de comparações. As lembranças sobrevieram na perspectiva das relações estabelecidas entre professor e aluno no tempo pretérito e, ao serem recontadas, obedeceram ao corte da autoridade do professor.

Partindo da expressão "no meu tempo"37, os informantes afirmaram:

"a criança aprendia mesmo, tinha medo da professora que era brava e deixava de castigo. Hoje a autoridade da professora foi retirada. Ela tem que ter autoridade porque ali ela está sendo mãe. Antes só ouvia a voz do professor. $O$ professor era forte e puxava a orelha. Hoje, 0 aluno não tem mais medo e o professor faz 0 que 0 aluno quer". 38

“Antes eu falava a tabuada da primeira à últi$\mathrm{ma}$, hoje a criança cola. A facilidade serve para a criança aproveitar do professor. Muitos alunos não sabem mas passam na prova de pesquisa. Antigamente o aluno ficava atento.

Hoje tá muito difícil. Essa amizade, democracia, liberdade de hoje (...). Até que voltem os tempos antigos onde o professor era respeitado (...) a TV estragada".39

"O professor era brabo, puxava cabelo e beliscava costela". 40 .

"Não faz tempo o professor suspendeu um aluno, não sei se foi certo ou errado mas tentou acertar. Escola não é prá ficar brincando".41

"A primeira professora vinha a cavalo ou de bicicleta. Os alunos eram tristes, pulavam por cima da mesa, tinha briga de pau. Hoje as crianças têm mais amizade do que antigamente só que antes eram briguentos mas aprendiam. A professora passava no quadro". 42

"Antes a professora era brava mas as crianças aprendiam, hoje não. É que retiraram a autori-

37 "No meu tempo" indica o passado dos adultos que relembram da escola vivida, num periodo variável entre 20 e 30 anos atrás.

38 Manifestação de uma mãe de aluno, na Escola Rosália Simm.

39 Pai de aluno na Escola Cachoerinha.

40 Entrevista coletiva realizada na Escola São Francisco.

41 Id. Ibid.

42 Id. Ibid. 
dade da professora, ela precisa ter autoridade. Quando a gente não fazia tarefa levava apagador na mão e puxão de orelha".43

O professor é representado, na ótica dos pais, como o responsável pela qualidade do ensino, organicamente ligada ao exercício da autoridade docente. Contudo essa autoridade é retratada através dos castigos e reprimendas como instrumentos didático-pedagógicos que, provocando respeito pelo medo, garantiam a eficiência da aprendizagem. Em oposição à esse entendimento, advindo do passado, as práticas pedagógicas do presente são sintetizadas na ausência de autoridade do professor. Essa ausência é responsável por um clima de amizade, falta de respeito e liberdade que serve à facilitação da aprendizagem. Aprender e ensinar são atividades incompativeis com brincadeiras, democracia e diálogo. A escola não precisa ser agradável e o professor que compactua com a lógica da democratização é visto como culpado pela desqualificação do nível de ensino. Nas representações dos pais a disciplina na escola é visualizada na ótica da formalidade como produto do exercício da autoridade docente, cuja falta gera a indisciplina. Não há também qualquer diferenciação entre autoridade e autoritarismo, assim como democratização da educação e facilitação da aprendizagem são expressões que se confundem. De acordo com José de Souza Martins, para as populações rurais.

\begin{abstract}
"a atividade escolar em si mesma [...] e independente do conteúdo do que ali se ensina, é considerada aprendizado: o estar submetido à disciplina do trabalho (escolar) e à obediência à autoridade de um professor. (...) Aí há, também, um querer da vítima que define a educação: ela a quer para se apossar da cultura, das técnicas e do saber de quem manda. Seja para simplesmente escapar do mando, mandando, ou escapar do mando utilizando contra o adversário o seu próprio saber". (MARTINS, 1992, p. 32).
\end{abstract}

Nessa perspectiva a transposição das experiências escolares do passado para o presente ganha um sentido definido. Na percepção dos pais, uma relação pedagógica austera, reflete o modelo considerado ideal de educação, cunhado na pedagogia tradicional. Para além do lado revelado está aquilo que se esconde e, por isto mesmo, constitui-se como elemento fundante da própria atividade escolar.

$\mathrm{Na}$ perspectiva do professor de escola rural isolada, o exercício de uma prática escolar estruturada na "palmatória" não se coaduna com as orientações recebidas da Secretaria e de Supervisores, e nem mesmo com a dinâmica da sociedade atual.
O trabalho docente na escola isolada inicia-se, muitas vezes, pelo desafio de superar a distância da escola, e ao chegar sabe-se que, além de ensinar, é preciso zelar pela conservação e limpeza da mesma, contando com a colaboração de alunos e, raras vezes, de merendeiras onde elas existem. Usualmente a própria professora é também a merendeira e a secretária da escola.

A partir dos anos 60, a Secretaria de Educação passou a selecionar professores através de concursos, de maneira que nomeação de docentes residentes nas proximidades das escolas só acontece em situações excepcionais. Desde que habilitado, o professor de escolas rurais recebe o mesmo salário do docente de escolas urbanas. Quando leigo, recebe $20 \%$ a menos. Nesta condição estão $30 \%$ dos professores rurais que ainda são leigos.

Os recursos didático-pedagógicos, muitas vezes, estão restritos ao quadro, giz e livro didático. Por isto quando se trata de ensinar aquilo que faz parte do cotidiano não surgem dificuldades, porém aquilo que não está contido nesse cotidiano, colocase num plano abstrato de dificil entendimento.

"Falar das coisas da fazenda é fácil, todos conhecem. Mas, tem alunos que nunca foram à cidade e falar de trânsito, por exemplo, é difícil". (Escolas..., 1993, p. 5).

O tempo dedicado ao ensino, na sala de aula é dividido em diferentes atividades para alunos de até quatro séries.

Quanto à realidade dos alunos, geralmente filhos de pequenos produtores e assalariados, basta mencionar que:

"a família não quer e não pode privar-se da colaboração dos filhos no trabalho do campo (...)." (BASSO et. al., 1993, p. 39).

Em face das ambigüidades e inseguranças postas pelo presente, o passado é refeito pelo tipo das lembranças como um tempo carregado de experiências positivas. A austeridade das relações pedagógicas é amenizada pelos bons resultados obtidos na transmissão e assimilação do conhecimento. Mesmo que os limites da escolaridade estivessem (em parte ainda estão) situados no ato de "tirar" a $4^{\mathrm{a}}$ série ou a aprender a ler escrever, a experiência escolar pretérita é referida como bem sucedida para os padrões do cotidiano vivido.

As relações de gênero, marcante visíveis na escola do passado, quando meninas se postavam num lado da sala de aula e meninos no lado oposto, surgiram nas falas dos entrevistados sempre que relembram dos professores (homens) como diferentes das professoras. Embora preservando a autoridade de ambos, o professor aparece como mais "forte" e "bravo".

Atualmente as facilidades de acesso ao meio rural, bem como a ampla penetração dos meios de comunicação de massa nos mais distantes recantos, 
demonstram que o rural encontra-se interpenetrado pelo urbano. Contudo é importante considerar, de acordo com BOSI, que:

"O povo assimila a seu modo, algumas imagens de televisão, alguns cantos e palavras do rádio, traduzindo os significantes no seu sistema de significados. Há um filtro, com rejeições maciças da matéria impertinente, e adaptações sensíveis da matéria assimilável". (1992, $p$. 329).

Desse modo, entende-se que a indústria cultural, acelera o processo de apropriação de imagens e signos que retrabalham as subjetividades mas, não se deve desconsiderar o peso das tradições e valores transmitidos ao longo de gerações que são elementos importantes das tramas de relações sociais tecidas entre os trabalhadores rurais.

Assim, é através da memória verbalizada que os sujeitos revelam como vivência a experiência escolar enraizada na cotidianidade do mundo rural. Orientados por uma visão de mundo, de homem e pelo próprio contexto em que suas práticas se concretizam; pelas necessidades, possibilidades e expectativas próprias da realidade sócio-cultural, os informantes apreendem a escola em sua dimensão simbólica, conferindo-lhe o papel de mediadora entre o presente, passado e futuro. A escola se coloca como:

"O lugar do entrecruzamento do projeto político coletivo da sociedade com os projetos pessoais e existenciais dos educandos e educadores".

(SEVERINO, 1992, p. 13).

As referências buscadas no passado para interpretar o presente, são reinterpretada pois é impossivel negar a dinâmica do tempo e das condições materiais. Assim, a educação rural, reiterpretada pelos entrevistados, não se separa das transformações da realidade e do cotidiano de trabalho do grupo social em que a escola está inserida. Isto implica em aprofundar o conhecimento sobre essa realidade para que as políticas educacionais e a educação formal fortaleçam o desejo de emancipação intelectual desse segmento social.

\section{A construção da resistência: cidadania revelada na escola rural isolada}

A reunião de parte das escolas isoladas em núcleos, demanda a ampliação ou construção destes para que abriguem os novos alunos e professores. Em 1993 a Secretaria de Educação chegou a propor a demolição das escolas desativadas para reutilizar
- material nas obras de ampliação ou construção dos núcleos escolares. 44

Observando o conjunto das relações sociais que caracterizam as comunidades rurais, é possivel afirmar que a escola, apesar de situar-se fora do sistema de produção, continua a ser um lugar de presença obrigatória na vida das crianças do meio rural. Ler e escrever é um instrumento político de construção da cidadania, de rompimento com a naturalização da inferioridade do homem rural. Exatamente por isto percebe-se uma certa resistência, em algumas comunidades quanto à proposta de demolição das escolas. Resistência justificada pois a escola é um ponto de referência, de sociabilidade onde acontecem festas, missas e reuniões comunitárias. Ainda hoje, a escola isolada, representa um laço muito forte entre o presente e o futuro, retratado na esperança de uma vida melhor. Não dispor da escola, na comunidade, sugere um sentimento de perda, diante da impossibilidade de concretizar o sonho de uma vida nova personificado na escola, como o lugar "mágico" que pode vir a materializar o sonho. 45

Presente e futuro estão na escola enlaçados às lembranças do passado. Enquanto relembram do tempo pretérito, os pais ressignificam a escola como um bem cultural que lhes pertence não só em decorrência dos encontros sociais ali realizados e das possibilidades futuras que a escola encerra. Mas, sobretudo, porque nas omissões do poder público, a comunidade se fez participativa consertando o piso, forrando a escola, construindo o poço e organizando festas para arrecadar fundos a fim de suprir suas carências.

Referindo-se ao processo sócio-histórico de apropriação dos bens culturais próximos das comunidades rurais e mais especificamente à escola, Ezpeleta e Rockwell, afirmam:

"Os habitantes se comprometem com a melhoria e a manutenção do prédio escolar. Levam em conta as exigências de "modernização" que caracterizam mais as escolas urbanas, mas também resistem à destruição daquilo que lhes custou um preço alto e reclamam contra os custos e qualidades questionáveis das escolas construídas pelas agências oficiais".

(EZPELETA \& ROCKWELL, 1989, p. 63-64).

Ainda que a oposição ao projeto de nucleação não tenha se constituído em uma ofensiva homogênea, as preocupações e dúvidas manifestadas pelos pais, traduziram a noção de pertencimento da "escolinha" na comunidade. A escola lhes pertence por que sua proximidade geográfica facilita os cuidados das crianças favorecendo o controle dos valores culturais que são disseminados na escola.

44 Atualmente, as comunidades rurais que desejam preservar os prédios de escolas desativadas são atendidas, desde que se responsabilizem pela manutenção dos mesmos.

45 BASSO, et.al., p.49. 
Os pais sentem-se mais presentes e por isto crêem que seus filhos, ao permanecerem na escola rural isolada, conservarão as raizes culturais rurais.

Tentar conservar as raízes é vital diante das transformações e crises que estamos vivendo, quando velhos problemas são repostos e novos são criados. O progresso técnico-científico anuncia a nova revolução que aspira, ao menos em tese, a eliminação do trabalho. Contraditória e simultaneamente à globalização econômica, dispersam-se pontos de referências, desenraízam-se coisas, gentes e idéias. Para IANNI:

"A desterritorialização manifesta-se tanto na esfera da economia como na da política e da cultura. Todos os níveis da vida social, em alguma medida são alcançados pelo deslocamento ou dissolução das fronteiras, raizes, centros decisórios, pontos de referência. As relações, os processos e estruturas globais fazem com que tudo se movimente em direções conhecidas e desconhecidas, conexas e contraditórias. (1992, p. 94).

Desterritorializar, na sociedade contemporânea, implica na diluição das fronteiras entre o urbano e o rural, para fazer emergir um modo de ser isento de espaços e tempos. Para tanto é preciso desenraizar a própria imaginação. Contudo ao incorporar certos significantes urbanos, a exemplo da inferioridade do rural, esse homem se coloca como produto histórico-social porém, ao resistir à sua desterritorialização, tomando a "escolinha" como uma mediação simbólica, se coloca como o produtor de sua história. Enquanto homens do campo eles recriam formas de ser, ainda que para isto, seja necessário revivificar valores que prevaleceram no passado, resistindo à expropriação e desenraizamento de si mesmos.

"somos caipiras, como nossas crianças vão se adaptar na cidade?"

"Aqui as crianças vão na escola de chinelo de dedo, não tem luxo e lá tem que ir de uniforme."

"A escola é boa quando está perto".

"Na escola nucleada as crianças poderão ser discriminadas".

"Se a criança se machuca de quem é a responsabilidade?"

"A cidade está cheia de crianças abandonadas."
"As crianças correm o risco de aprender malandragem." 46

A cidade é representada como um lugar complexo, distante, perigoso e radicalmente diferente quanto ao estilo de vida e normas de comportamento. A princípio prevaleceu o entendimento de que o agrupamento seria realizado em escolas da cidade, tal como ocorre com uma parcela de estudantes rurais do $2^{\circ}$ grau. Entretanto, nas representações das pessoas que residem em sítios, a cidade está simbolizada pela sede do distrito rural, que contém influências similares ao espaço urbano do distrito sede.

Advogando a eficiência da proposta de nucleação, os representantes do poder público municipal, utilizaram (nas reuniões realizadas com as comunidades incluidas no projeto) argumentos qualitativos e quantitativos, tais como: presença constante da supervisão na escola nucleada, assistência médica e odontológica mais próximas; existência de biblioteca, merenda, aulas e recreação; facilidade na socialização das crianças, melhoria sensível do nível de ensino, maior quantidade e variedade de material didático, facilidade de transporte a custo zero.

Mesmo diante desse discurso, os pais opuseram resistências ancoradas, ora na trajetória histórica da escola, inseparável da própria história da comunidade, ora em preocupações que denotam uma certa descrença na propalada eficiência do poder público. Neste rol estão as preocupações relativas ao transporte: riscos de acidente, assaltos e estradas perigosas, especialmente nos dias chuvosos quando as estradas de terra ficam intransitáveis. Existe 0 receio de que o Município não melhore as condições dessas estradas. Isto é indispensável para garantir a presença das crianças na escola nucleada. De fato, os pais não são contrários à nucleação e à melhoria do nível de ensino, eles se opõem à destruição dos seus referenciais culturais.

Explicitando suas preocupações os pais, aos poucos, foram opondo limites ao poder decisório do Estado, tendo este recuado quanto à demolição das escolas desativadas. Além disso foi pressionado para garantir transporte seguro, estradas adequadas, protelou a desativação de escolas e restruturou sua proposta inicial acatando o desejo de moradores no sentido de construir núcleos na zona rural e com isto diminuiu a resistência ao projeto de nucleação.

E importante ressaltar novamente que a resistência não se constituiu como um todo homogêneo. Os trabalhadores temporários demonstraram ser menos resistentes à escola na cidade, enquanto os pequenos proprietários, meeiros etc..., evidenciaram seus temores invariavelmente ligados à idéia de preservação da cultura característica do mundo

46 Preocupações manifestadas nas escolas Rosária Simm, Cachoeirinha e André Rebouças entre outras. 
rural, a manutenção da propriedade e ao receio de que seus filhos, seduzidos pelo mundo urbano, negassem 0 trabalho no campo. À medida que esses proprietários buscam garantir o direito à escola no meio rural, vivenciam momentos político-educativos de reafirmação da identidade e da cidadania como sujeitos que intentam rupturizar com a lógica da subalternidade. Para tanto necessário se faz defender a permanência da escola isolada. Sua desativação provoca também o temor quanto ao aumento da analfabetismo no campo. De fato, a apropriação do conhecimento, além de se constituir em um direito, é elemento constitutivo da própria condição humana e uma exigência da cidadania.

Nessa direção podemos concordar com Slhessarenko, quando afirma:

"O campo social, onde a educação se situa, torna-se a arena do confronto político dos interesses de classe e de luta pela cidadania, a qual aparece, cada vez mais, como algo incompativel com um determinado nível de desigualdade". (1992, p. 28).

A palavra cidadania expressa um direito e também o exercício desse direito, desdobrado em outros tantos. O sujeito cidadão se configura a partir das interelações que estabelece com a natureza e com a sociedade; relações que, inevitavelmente, encontram-se perpassadas por intencionalidades subjetivas e determinações objetivas. É interessante notar que a palavra rural, provém do latim Rus que significa rústico, rude tosco, grosseiro. Em oposição está a palavra cidade que vem do latim CIVITAS ou o mesmo que civilização e do grego POLIS significando o mesmo que polido. Historicamente a cidade constituiu-se como espaço dos homens livres e, por consequência, do exercício da cidadania; enquanto ao homem do campo destinava-se apenas o trabalho rude da lavra da terra, entendido como Tripalium. Essa capa ideológica contribuiu durante séculos para reproduzir a noção de que ao homem do campo restava a resignação.

Enfocando as especificidades da cultura camponesa, José de Souza Martins explica:

"Mais forte nessa cultura popular não é o que nela se revela (e se fala!), mas o que nela se esconde. (...) As condições da dominação branca e colonial, e seus desdobramentos até a época atual, impuseram ao camponês a necessidade vital de usar permanentemente táticas de dissimulação para sobreviver física e culturalmente." (1992, p. 33).

Nessa perspectiva é possível pensar que a resignação à uma condição humana subalterna tenha se erigido como forma de garantir a própria sobrevivência.
"O caráter submisso do camponês, reiteradamente salientado até mesmo por antropólogos e sociológos, é apenas um dos lados dessa manipulação de aparências e de culturas - é técnica de sobrevivência. Essa parece ser a razão da facilidade com que camponeses (...) assimilam componentes da cultura dominante (...). Mas, há que considerar que nessa disponibilidade para assimilar a cultura do outro, entra também a necessidade de manejar essa cultura em defesa daquilo que é essencial e vital na cultura do camponês (...). (MARTINS, 1992, p. 33).

Para sintetizar, pode-se afirmar com Severino que:

"a cidadania exige o efetivo compartilhar das mediações existenciais; e essas mediações assumem três configurações dialeticamente articuladas e dependentes entre si (...) o compartilhar dos bens materiais (...), dos bens simbóli$\cos (\ldots)$ [e] dos bens sociais (...)" $(1992, p .11)$.

Na perspectiva dos informantes, o exercício da cidadania está ligado à preservação do próprio ambiente em sua dimensão física que, no caso, é representado pelo prédio da escola. Mas, o prédio contempla uma dimensão simbólica que é colocada em cena a medida que a concretização do processo de agrupamento se aproxima. Defender a "escolinha" significa garantir as condições necessárias para que as crianças se apropriem do universo cultural inclusivo. Contraditoriamente essa resistência aparenta ser "conservadora e oposta ao sentido da História", no entanto:

"São os valores que fazem com que a ação tenha sentido para todos, especialmente porque neles está contida a construção em comum daquilo que dá sentido à humanidade do Homem". (MARTINS, 1992, p. 30).

Nessa construção não se vê resistência às inovações que são aspiradas e aceitas; não se vê mera tendência ao conservadorismo, mas uma desconfiança obstinada quanto aos propósitos contidos na política de nucleação e uma resistência acirrada para aceitar a própria destruição. Considerando, de outro ângulo, parece que a proposta de agrupamento escolar no meio rural, acompanhada de uma boa estrutura de transporte, poderá contribuir para a permanência dessas famílias no campo.

\section{Notas inconclusas}

As discussões que se anteciparam à concretização da proposta de nucleação das "escolinhas", constituiram-se como verdadeiros espaços de exercício da cidadania, nos quais se confrontaram produtores rurais e o poder público. Diante do "novo" e desconhecido eles revivificaram a própria história 
da escola, expressaram seus receios e desconfianças; reforçaram seus laços de identidade coletiva e acima de tudo, puseram a tona a importância que imprimem aos bens culturais que lhes pertencem. Evidenciando suas subjetividades, muitas vezes desconsideradas nos planos oficiais, transformamnas em espécies de trincheiras protetoras da invasão dos estranhos e do avanço das forças expropriadoras e desenraizantes do capitalismo.

Aos poucos o projeto de nucleação vem ganhando espaços. Embora essa morosidade possa ser reputada à carência de recursos públicos disponíveis para garantir o transporte das crianças, bem como, à necessidade de ampliação das escolas - núcleos e, até mesmo, a exigida adequação das estradas, ainda assim, é o sinal evidente de que o poder público tem usado de cautela, recuando inclusive quanto à demolição das escolas desativadas.

De maneira geral, pode-se afirmar que, do ponto de vista das finalidades sócio-políticas e das condições reais, a educação rural em Londrina e no norte paranaense não ficou imune aos propósitos das políticas de educação rural. A própria expansão das escolas rurais isoladas não se explica apenas pela expansão da cafeicultura, mas também através de movimentos que vem de cima para baixo ou de fora para dentro, inserindo-se em determinadas políticas formuladas a nível macrossocial, geralmente embasadas em conteúdos ideológicos cambiantes ao sabor dos interesses políticoeconômicos prevalecentes.

Apesar das constantes e insistentes influências do urbano que são carreadas para o mundo rural, através dos mais diferentes produtos da industria cultural e da informação, a escola rural mantém certas especificidades. Afirmando suas singularidades não se quer dizer que esteja desligada do contexto em que se insere. Contrariamente constitui a um só tempo, síntese e antítese das determinações históricas ali concretizadas, isto é, a escola é um lugar que sintetiza as contradições e cria a possibilidade dos atores sociais se tornarem sujeitos da história.

Como um espaço que não se explica por si mesmo, a escola rural isolada, é importante referência cultural entre certos grupos de trabalhadores rurais que nela simbolizam a própria coesão social e as permanências desejadas, em oposição às tentativas de desenraizamento ancorado na fragilização dos elementos que compõem o imaginário social. O exercício da cidadania, no caso especifico das comunidades que se opuseram à proposta de agrupamento, encontra-se ligado à revalorização da "escolinha" como o local de sociabilidade e de esperanças futuras. Assim sendo, a luta para preservá-la é também uma luta pela própria identidade coletiva frente às insistentes formas de exclusão do homem do campo. A "escolinha" lhes pertence e garantir esse pertencimento é uma maneira de amenizar a suscetibilidade a que fica sujeita a educação formal no campo face as variações das políticas públicas.

Os processos interativos que são tecidos nas instituições escolares tanto podem contribuir para reproduzir o estabelecido, como podem instar formas de superação. Um conhecimento mais profundo da cultura camponesa se põe como fundamental para se pensar numa proposta escolar que não seja meramente reprodutora, mesmo porque a educação "torna-se a arena do confronto político dos interesses de classe e de luta pela cidadania", que na sociedade contemporânea está indissoluvelmente associada à apropriação mais igualitária do conhecimento.

Embora seja arriscado falar, em bases consensuais, de um modelo adequado de organização da educação rural, não se pode negar que a escola configura-se como um fator diferencial. A apropriação dos códigos escolares pelos trabalhadores do campo, ligada à necessidade de se manterem na terra, pode constituir-se numa importante mediação do processo de construção de uma cidadania autenticamente rural.

\section{Referências Bibliográficas}

\section{BASSO, I.C.; MENDES, J.P.; SANTOS, M. dos} Escola rurais isoladas do município de Londrina: uma breve abordagem. Piracicaba: Universidade Metodista de Piracicaba, 1993. Mimeografado.

BOSI, Alfredo. Dialética da colonização. São Paulo: Companhia das Letras, 1992

DAVIS, C.; GATTI, B. A. A Dinâmica da Sala de Aula na Escola Rural. In: THERRIEN, J., DAMASCENO, M.N. (Coords). Educaçãoe escola no campo. Campinas: Papirus, 1993.

ESCOLAS Rurais a Caminhos do Fim. Folha de Londrina. Londrina, p. 5, 18 set. 1993. Folha Rural.

ESPELETA, Justa; ROCKWELL, Elsie. Pesquisa Participante. São Paulo: Cortez, 1989.

IANNI, Otávio. A Sociedade global. Rio de Janeiro: Civilização Brasileira, 1992.

MARTINS, J. de S. Educação e Cultura nas Lutas do Campo: Reflexões sobre uma Pedagogia do Conflito. In: Sociedade Civil e Educação Coletânea CBE. São Paulo: Papirus, 1992.

SEVERINO, A.J. A Escola e a Construção da Cidadania. In: Sociedade Civil e Educação Coletânea CBE. São Paulo: Papirus, 1992.

SLHESSARENKO, Serys M. Escola e a Construção da Cidadania: novas concepções e novas alternativas. In: Sociedade Civil e Educação Coletânea CBE. São Paulo: Papirus, 1992. 